\title{
Current state of art of satellite altimetry
}

\author{
Adam Bolesław Lyszkowicz ${ }^{*}$, Anna Bernatowicz ${ }^{2}$ \\ ${ }^{1}$ Polish Air Force Academy \\ Department of Air Navigation \\ 08-521 Dęblin, Dywizjonu 303 \\ ${ }^{2}$ Koszalin University of Technology \\ Chair of and Surveying \\ 75-453 Koszalin, Śniadeckich 2 \\ e-mails: 1adaml@uwm.edu.pl; ${ }^{2}$ agosn@wp.pll
}

Anna Bernatowicz: https://orcid.org/0000-0002-0455-2457

Adam Łyszkowicz: https://orcid.org/0000-0002-8363-6076

* Corresponding author: Adam Bolesław Łyszkowicz

Received: 30 June 2017 / Accepted: 24 August 2017

\begin{abstract}
One of the fundamental problems of modern geodesy is precise definition of the gravitational field and its changes in time. This is essential in positioning and navigation, geophysics, geodynamics, oceanography and other sciences related to the climate and Earth's environment. One of the major sources of gravity data is satellite altimetry that provides gravity data with almost $75 \%$ surface of the Earth. Satellite altimetry also provides data to study local, regional and global geophysical processes, the geoid model in the areas of oceans and seas. This technique can be successfully used to study the ocean mean dynamic topography. The results of the investigations and possible products of altimetry will provide a good material for the GGOS (Global Geodetic Observing System) and institutions of IAS (International Altimetry Service).

This paper presents the achievements in satellite altimetry in all the above disciplines obtained in the last years. First very shorly basic concept of satellite altimetry is given. In order to obtain the highest accuracy on range measurements over the ocean improved of altimetry waveforms performed on the ground is described. Next, significant improvements of sea and ocean gravity anomalies models developed presently is shown. Study of sea level and its extremes examined, around European and Australian coasts using tide gauges data and satellite altimetry measurements were described. Then investigations of the phenomenon of the ocean tides, calibration of altimeters, studies of rivers and ice-sheets in the last years are given.
\end{abstract}

Keywords: satellite altimetry, radar altimeter, waveform retracker, ocean gravity field model, sea level, gravity anomalies, ocean tides 


\section{Introduction}

One of the basic problems of modern geodesy is an accurate determination of the gravity field and its temporal variations. This is important for applications in geodesy, navigation, geophysics, geodynamics, oceanography and other disciplines related to climate and environment of the Earth.

The International Association of Geodesy (IAG) Commission 2 is responsible for the coordination of these investigations. As a part of the Commission 2 there is a SubCommission 2.5 which has been established specially for the satellite technique.

Satellite altimetry is one of the recently developed new techniques of satellite geodesy. This method is particularly useful over the oceans because of the good reflective properties of the water. With this technique a lots of data was obtained from current altimetry missions and this led to important results in geodesy, geophysics and oceanography. Detailed information about a principle of satellite altimetry can be found in many excellent publications and books.

This new method is a broad area that includes many of the problems. Because of this multiplicity and possibilities offered by satellite altimetry, in the last few years, many important studies have been performed into development of altimeter waveform retrackers, improvement of regional and global sea and ocean gravity field models, studies of sea-level extremes, improvement of dynamic ocean topography models, modelling and assessing of ocean tides and calibration of altimetry data. The studies have concerned also applications of satellite altimetry over ice-covered and river surfaces. The most significant achievement is the more accurate marine gravity field models (accuracy $\sim 2 \mathrm{mGal}$ ) and ocean mean dynamic topography models Therefore, the aim of this paper is to present the progress that has been made in recent years in this discipline.

\section{Basic concept of satellite altimetry}

Satellite altimetry is a radar technique of measuring the distance, based on a simple principle of functioning. It aims to determine the distance from the satellite to the ocean surface using radar signal. From such a distance measurement a lot of other valuable information about the gravity field of the Earth, changes of the oceans, the climate and the environment are delivered.

First useful measurements, made to determine the ocean surface topography using radar equipment combined with a technique of satellite positioning, were done by the Seasat mission in 1978, then Geosat in 1985 and ERS1 in 1991.

Since then many new missions were launched (Figure 1). They constantly provide various data of better quality. Currently, as part of altimetry missions, satellites Jason-2/-3, Cryosat-2, HY-2, Saral, Jason-3 and Sentinel-3 are operating: http://www. aviso.altimetry.fr/en/missions/current-missions.html 


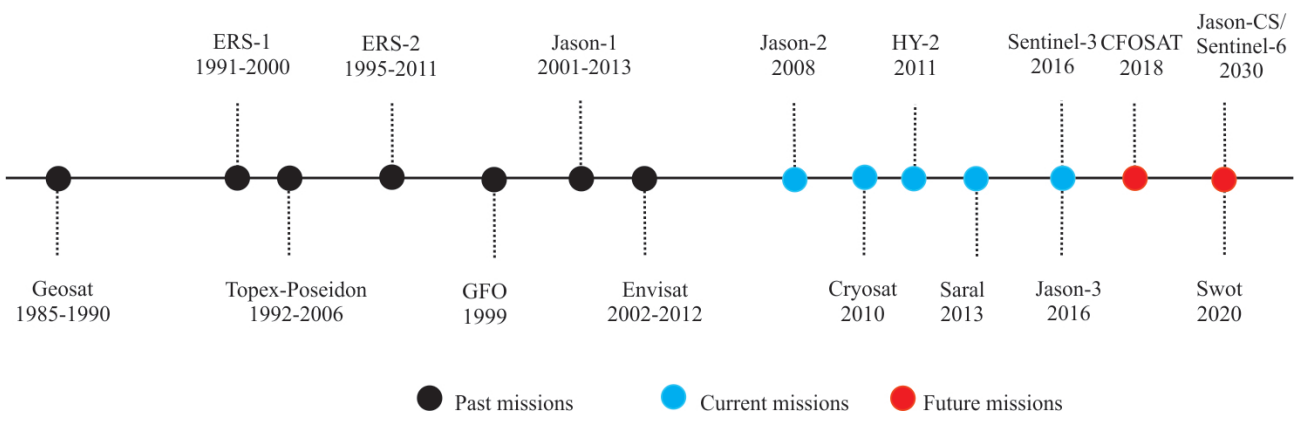

Fig. 1 Past, current and future altimetry mission

(based on http://www.aviso.altimetry.fr/en/missions.html)

Principle of this satellite technique is that the altimeter placed on a satellite, emits a radar wave (signal) in the direction of the Earth's surface. This radar wave is reflected by the Earth's surface and the satellite receives the reflected signal. The time elapsed between transmission and receiving of the radar signal is proportional to the height of satellite. Data processing allows determining the distances between the satellite and the instantaneous ocean's surface. These distances, with a precisely determined orbit, give the sea surface height relative to a reference ellipsoid.

Waveform (the magnitude and shape of the radar altimetry return signal) also contains information about the characteristics of the surface which caused the reflection of echo. The echo waveform, over the ocean's surface, has a characteristic shape that can be described analytically (the Brown model). Considering the reflected wave's amplitude and its track it can be measured also the height of the sea wave and wind speed over the oceans. More generally backscatter and roughness coefficients of the ocean surface.

Over ground surfaces the return signal depends on the surface characteristics which can also change in time. This means that each single signal must be carefully analyzed and processed. Therefore, in order to obtain altimetry observations a complex procedure using special algorithms must be carried out.

\section{Improved of altimetry waveforms}

In order to obtain the highest possible accuracy on range measurements over the ocean, today's altimeters downlink the waveforms to Earth and the final retrieval of geophysical parameters from the waveforms are performed on the ground. This is called "waveform retracking". The aim of the ground-based retracking is to fit a model or functional form to the measured waveforms, and retrieve geophysical parameters such as the range, echo power. Functional forms can be purely empirical, or as in the case of the Brown ocean retracker, be based on physics. 
A new system CAWRES (Coastal Altimetry Waveform Retracking Expert System) was developed by e.g. (Idris and Deng, 2012) to obtain the most beneficial altimetric sea levels from multiple retracking solutions nears the coast. The system works in two steps. First altimeter waveforms are reprocessed by system using optimal retracker, and then the relative offset in the retrieved sea levels is minimized. The subwaveform retracker used in system causes that Brown model fits to the truncated waveform samples corresponding to waveform reflected from the water surface.

A two-pass retracking method to improve the accuracy of sea surface slopes derived from multiple altimetric missions was used by (Garcia et al., 2014). This procedure has also been used in other studies e.g. by (Andersen et al., 2014).

In order to obtain the gravity anomalies from altimetry measurements with an accuracy of $1 \mathrm{mGal}$ the altimeter profiles with accuracy of $1 \mu \mathrm{rad}$ must be constructed. For this reason an iterative least-squares algorithm for the shape of the CryoSat-2 SAR waveform was used by (Garcia et al., 2014). Compared to conventional waveforms, the two-pass retracking procedure has resulted in a factor of $\sim 1.5$ improvement in range precision. The improved waveforms and their precision and dense coverage from CryoSat-2, Envisat and Jason-1 GM have caused a significant increase in the accuracy of the new global marine gravity field model.

In coastal seas $(0.5-7 \mathrm{~km}$ from the coast), over lakes and land waveform retracking has been examined. An example would be a new algorithm (Tseng et al., 2013) used in four regions of North America using Envisat and Jason-2 altimetry $20 \mathrm{~Hz}$ waveform data. In the waveform retracking process the algorithm modifies coastal waveforms and minimizes the error in the determination of the leading edge and associated track offset. Such approach increases the accuracy and coverage of coastal data. The received data from newer radar technique in the $1-7 \mathrm{~km}$ coastal area show a $63 \%$ improvement in accuracy compared to algorithms used for deep ocean waters. Techniques of retracking are also applied to altimeter data over areas with potential land subsidence.

To improve gravity anomalies and the precision of altimeter-derived sea surface heights (Yang et al., 2011) has created a threshold subwave form retracker based on a correlation analysis. After application of the retracker in theAntarctic Ocean study it found out that precision of gravity anomalies up to $46.6 \%$ compared to shipborne gravity anomalies.

\section{Significant improvement of sea and ocean gravity anomalies}

Gravity field models are important tools for display of tectonic structures, especially for deep ocean basins, where their topography cannot be determined by marine vessels or where it is covered by dense sediment.

For the first time, global marine gravity field model from satellite altimetry data was performed by (Andersen and Knudsen, 2000). Since that time many models i.e. from ERS-1 mission data were constructed e.g. (Andersen et al., 2005). 
With a new altimeter observation from Envisat, Jason-1 and CryoSat-2 the influence on global marine gravity field, in particular within the Arctic area, is significant. The most dense track coverage with a nominal track spacing of about $2.5 \mathrm{~km}$, after 4-years mission was provided by CryoSat-2 (Sandwell et al., 2014). Mission of Jason-1 delivered 14 months of dense track coverage, as a result in a track spacing of $7.5 \mathrm{~km}$, while the Envisat satellite mission collected 18 months of data with dense coverage in polar areas. The global marine gravity field has been improved with these new altimeter data sets by a factor 2 to 4 . In addition, the results of satellite altimetry with higher precision (1.25-times) have resulted in improvement in range precision of gravity field models. Using these data sets a new global marine gravity field model with an accuracy of $\sim 2 \mathrm{mGal}$ was constructed by (Sandwell et al., 2014) in which the most improvement the quality of the model is in the wavelength band $12-40 \mathrm{~km}$. This improvement permits to study the small-scale seafloor structures $(\sim 6 \mathrm{~km})$, which was not feasible by the past marine gravity models. It is an important tool for exploring the deep ocean basins and the accuracy achieved refers to all marine areas and large inland bodies of water.

With accuracy, represents by a new model ( $\sim 2 \mathrm{mGal})$, it is important to consider altimeter slope correction. This correction is used to calculate the height of the sea surface to minimize the impact of the sea surface slope. In previous altimetric studies influence of altimeter slope correction relative to the sea surface has been neglected due to the low accuracy of the gravity data. A global correction grid that can be scaled to the real altitude of any radar altimeter was constructed by (Sandwell et al., 2014).

Another global marine gravity field model was produced by (Andersen et al., 2014) from Technical University of Denmark (DTU) and is called the DTU13. To create this model all available altimeter data sets, including Cryosat-2 and Jason-1 data were used. Observations from Cryosat-2 enabled to complete imaging of the Arctic Ocean. The base of this model is retracked altimetric sea surface heights. Model DTU13 MSS (Mean Sea Surface) is with a high resolution of $1^{\prime} \times 1^{\prime}(2 \mathrm{~km} \times 2 \mathrm{~km})$ and the mean square error RMS is smaller than $1 \mathrm{~cm}$ except for the Wedell Sea and the north of Greenland where it exceeds $10 \mathrm{~cm}$.

The latest model released by researchers from the DTU is DTU15 combines MSS, MDT (Mean Dynamic Topography) and geoid models. The inclusion of almost four years SAR, LRM and SAR -In from CryoSat-2 data have proven to be major step forward in using satellite altimetry in the Arctic and show good agreement with airborne data and the Arctic Ocean circulation models.

Not so long ago gravity anomalies have been determined on the basis of the land, airborne and shipborne measurements. Since a new radar technique appeared it was possible to use altimetry data to calculate the gravity anomalies. Grids of free-air and Bouguer gravity anomalies around Taiwan with resolution of 1'x1' based on mentioned above different kind of terrestrial measurements and altimetry observations were constructed by (Hwang et al., 2014). To proper retrack waveforms modeling there were used various data from different satellite altimetry missions: Geosat GM, ERS-1 GM, Geosat/ERM, ERS-1/35d, ERS-2/35d, Jason-1 GM and TOPEX/Poseidon. These 
retracked data sets, together with Cryosat-2 LRM data retracked at the RADS (Radar Altimeter Database System) enabled to get, for waters around Taiwan and the South China Sea, regional marine gravity anomalies. Shipborne gravity anomalies which can be used to validate altimetry measurements were derived from marine gravity measurements using small and large vessels. (Hwang et al., 2014) combined in a onestep procedure, all kinds of data, by the band-limited least-squares collocation. The new anomaly grids show incredible tectonic features that can replace earlier results, and can be used in different applications.

\section{Studies of extreme sea levels}

In general the sea level is determined by the average level for the sea waters measured between the rise and fall of sea. An appropriate determination of sea level is extremely important in geodesy because it is geodetic reference surface for heights.

Sea level and its extremes have been examined, around European and Australian coasts using tide gauges data and satellite altimetry measurements. Data from various altimetry missions like TOPEX/Poseidon and Jason1 and Jason 2 with 14 tide gauges recorders over the past 20 years (1993-2012), have been combined to obtain proper sight of sea level. These common data were modelled using the multivariate regression method by e.g. (Deng et al., 2012) and the Multi Adaptive Regression Splines approach by (Gharineiat and Deng, 2015). These methods have been used to investigate six tropical cyclones and the results show that both methods, especially MARS can be used to study the effective monitoring of extremes sea level. The results also suggest that satellite altimetry is able to capture high sea level caused by violent hurricanes or cyclones.

As regards to obtaining the proper sea level, studies of e.g. (Cheng and Andersen, 2012) proved the importance of optimal tide modeling and careful use of dynamic atmosphere correction provided by the model MOG2D (2 Dimensions Gravity Waves Model). The study shows that the results obtained from satellite altimetry observations open the way for further research into monitoring of extreme sea level occurrences.

\section{Dynamic Ocean Topography and ocean circulation modeling}

The main aim of estimating a global MDT (Mean Dynamic Topography) is to obtain ocean dynamic topography in reference to the altimeter SLA (Sea Level Anomalies) computed relative to a 20 years (1993-2012) mean profile. Since 1992, there has been a significant improvement in modeling of the more detailed and accurate ocean mean dynamic topography. This improvement has been obtained due to a high resolution GOCE gravity model and data from satellite altimetric mission for a new MSS (Mean Sea Surface) by .e.g. (Knudsen et. al., 2011). 
A global model MDT based on two months of GOCE data and DTU10MSS constructed by (Knudsen et al., 2011), clearly shows the features of the ocean's steady-state circulation. Another model using 12 months of GOCE observations has been computed by (Albertella et al., 2012). The error estimate of this MDT in the Southern Ocean was achieved $\sim 7 \mathrm{~cm} / \mathrm{s}$.

The dynamics of ocean topography is associated with the phenomenon of water circulation. This occurrence has a big influence on local and regional climate phenomena. Because of the circulation, ocean mass changes its temperature which has a significant influence on the pressure distribution and atmospheric circulation. Hence, one of the major satellite altimetry goals is to study the ocean currents circulation. (Bosh et al., 2013) has undertaken the estimation the instantaneous dynamic topography iDOT (Instantaneous Dynamic Ocean Topography Profiles) on individual altimeter profiles. Determination of the instantaneous dynamic topography is possible after precise cross- calibration of altimetry data and after systematic filtering and subtracting sea surface heights and geoid height obtained from the GOCE-based GOCO03S gravity field model.

\section{Studies of rivers and ice-sheets}

Scientific studies using satellite altimetry also are related to altimetry application over ice sheets on the surface of lakes, seas, oceans and rivers. For the first time, using a time-series ICE- Sat/GLAS data, the map of the ice sheets heights relative to sea level (freeboard map ${ }^{1}$ ) was constructed by (Wang et al., 2014). This map with accuracy about $\pm 0,5 \mathrm{~m}$ was created for the giant iceberg generated by the collapsed Mertz Ice Tongue in February 2010. There was also found out, based on altimetry and remote sensing data that the freeboard varied from $23 \mathrm{~m}$ to $59 \mathrm{~m}$ and mean is $41 \mathrm{~m}$. With the assumption of hydrostatic equilibrium, the minimum was calculated as $210 \mathrm{~m}$, maximum as $550 \mathrm{~m}$ and average ice thickness was calculated as $383 \mathrm{~m}$. The total ice loss was estimated as $\sim 8.96 \times 1011$ tons. This study has shown that altimetry data can provide additional information for studies of the evolution of icebergs and their monitoring.

Other researchers have been too interested in application of satellite altimetry for studies ice sheets. For example ice-sheet elevation change rates over mountain Glacier were investigated by (Lee et al., 2013). This method can be applied to other global glaciers (more than $7 \mathrm{~km}$ ), and can provide new point of view into the behavior of glaciers in relation to the climate changes.

For some areas with rivers and lakes the hydrological information are difficult to obtain. In general, the problem is due to the lack of direct access to these places. Therefore, satellite altimetry allows monitoring changes over inland water levels. Currently, a large number of various sizes lakes and rivers are monitored

1 Freeboard is defined as the vertical height of the ice shelf or sea ice above sea level. 
by satellite altimetry. Numerous studies of modelling water levels over rivers have been conducted. Indonesian small rivers (width $<1 \mathrm{~km}$ ), Bangladesh river deltas and Amazon basin rivers were studied by e.g. (Sulistioadi et al., 2015). Areas in Indonesia and Bangladesh are a scientific challenge for the satellite technique. Because of small reflecting area covered by satellite there are places where are large spatial and temporal sampling gaps The studies have shown the ability of satellite altimetry to monitor small water bodies and river deltas in Asia.

The inter-annual water storage changes in the Aral sea has been studied by (Singh et al., 2012) by using multi-mission altimetry, remote sensing data and GRACE observations.

\section{Ocean tides}

The oceans are in constant motion. Tides change sea level and cause the formation of strong local currents. One of the satellite altimetry goals is to investigation of the phenomenon of the ocean tides. Study has been made together with modelling an ocean tide models derived from altimetry and GRACE observations and estimated global (and regional) barotropic ocean tide models (whose density is a function of pressure) by e.g. (Stammer et al., 2014). Altimetry and GRACE measurements, were used to produce a combined estimation of a global ocean tide model E0T08ag (Empirical Ocean Tide Model 2008) by (Mayer-Gurr et al., 2012). The participation of differential data from GRACE to E0T08ag model is small and is mainly concentrated to the Arctic Ocean where are little or poor altimetry data. Data from this mission did not have much influence on improvement in other applications of satellite altimetry. They only caused improvement in the ocean tide model. The exception is in a few areas above $60^{\circ} \mathrm{N}$.

The successor model of EOT08ag is EOT11a. It was developed by (Savcenko and Bosch, 2012) and is based only on empirical analysis of satellite altimetry data. EOT11a model will serve as the basis for subsequent EOT models.

Authors (Stammer et al., 2014) assessed the accuracy of the latest global barotropic tide models. The accuracy was determined using bottom pressure data, satellite altimetry, coastal tide gauges, diverse geodetic data on Antarctic ice shelves, and independent tracked satellite orbit perturbations. Errors which were obtained from differences between tide observations and the best models for eight major components are $\sim 0.9 \mathrm{~cm}$ for pelagic, $\sim 5.0 \mathrm{~cm}$ for shelf and $\sim 6.5 \mathrm{~cm}$ for coastal conditions. In high latitudes occur large intermodel discrepancies, but testing in those regions is difficult because of lack of high-quality in situ tide records.

Tide parameters obtained from ground observations i.e. from tide gauges can be used to control the regional data with global ocean tide models. Six global models, i.e.: EOT11a, EOT10a, EOT08a, FES2004, TPXO.7.2 and GOT4.7 were examined by (Richter et al., 2012) based on pressure tide gauge observations at three sites of the Atlantic coast of main island Tierra del Fuego. From these data were derived the 
time series of bottom pressure and sea-level variations. The tidal signal represented by different global tide models, in aspect of time, deviates by a few decimeters from tide gauges data. Relative sea-level variations derived from the altimetry data have the accuracy of the order of $5 \mathrm{~cm}$.

\section{Calibration of altimeters}

As with all geodetic instruments, a calibration of the satellite altimeter must be performed to estimate the error characteristics of the instrument.

Altimeter performs on board the satellite internal calibration to observe any relative range changes in the instrument. However, due to the slope and drifts of the instrument it needs perform also external calibration. Furthermore, proper calibration of many satellite altimeters allows for a comparison of scientific results which can include all decades of observations.

Thanks to satellite altimetry it is possible to observe more than 20 years of global and regional changes in sea level. Twenty years of data records need to be store from various satellite altimetry systems. These data from a partly overlapping altimeter missions allow carefully cross-calibration between different altimeter missions by insitu sites. Global cross-calibration through adjusting a really large set of crossover differences performed between all present altimeter systems has been realized by e.g. (Bosch et. al, 2014). The entire set of these differences creates a highly redundant network and enables a robust estimate of radial errors with a dense and sampling for all examined altimeter systems.

Long term changes in the TOPEX/Jason range corrections at four altimetry calibration sites namely: Bass Strait, Corsica, Gavdos and platform Harvest have been investigated by (Andersen and Cheng, 2013). The results of these studies show that there are no meaningful linear trends in the sum of range corrections at the calibrations sites within $50 \mathrm{~km}$ (local scale) and $300 \mathrm{~km}$ (regional scale) around the selected site. However, dynamic atmosphere correction should be used with caution, because it is close to $1 \mathrm{~mm} /$ year at Mediterranean calibration sites.

\section{Further development of satellite altimetry}

The IAG Sub-Commission 2.5 appointed especially to the satellite altimetry is continuing studies in altimetric discipline. In 2011-2015 the Sub-Commission 2.5 performed diverse research focused on:

- improvement of global and regional marine gravity field models,

- improvement of dynamic ocean topography models,

- modelling and assessment of ocean tides and,

- calibration of data from satellite altimetry and,

- improvement of altimeter waveform retrackers. 
With accumulated information and recent progress in improvement of altimeter accuracy measurements, there can be a further improvement of the high- resolution and accuracy of global marine gravity field. InSAR/SAR and laser altimetry data respectively, from Cryosat-2 and Icesat-1/-2 mission significantly improve the cryosphere's observations and sea-ice and ice-covered oceans. Conventional LRM (Low Resolution Mode) and SAR (Synthetic Aperture Radar) modes of Cryosat-2, in the near future, will be the best chance to (double) improve seas and ocean gravity field by a factor of two.

Based on expected future data collection from Cryosat-2 and Sentinel-3 mission, further improvements are planned in modeling dynamic ocean topography and tidal ocean especially in near polar area. There are continued research in examination and modelling of sea-level rise and extremes and in monitoring of water level heights over inland water and ice sheets.

The goal of future planned for 2020 missions is to develop the land hydrology and oceanography surface topography model. It will be based on KaRIN (Ka-band Radar INterferometer) measurement mode.

Further improvements can be associated with development of advanced techniques to process altimeter SAR mode data and LRM data in coastal area by optimizing waveform retracking. Another potential technology which is interested in the satellite altimetry is the so-called GNSS-R altimetry or reflectometry. This technique is based on making measurements obtained from the reflection from the Earth of navigation signals from Global Navigation Satellite System. With the results from new and existing radar technique there is undoubtedly possible further improvement of final products used in various fields of life.

\section{Acknowledgements}

The study was carried out in the frame of statutory researches i.e. "Using the satellite techniques in geodesy and navigation" and "Aplication of a new geodetic technic in study figure of the Earth".

\section{References}

Albertella, A., Savcenko R., Janjic T., Rummel R., Bosch, W. and Schröter, J. (2012). High resolution dynamic ocean topography in the Southern Ocean from GOCE. Geophysical Journal International, 190(2), 22-930. DOI: 10.1007/978-3-642-37222-3_10

Andersen, O.B. and Knudsen, P. (2000). The role of satellite altimetry in gravity field modelling in coastal areas. Physics and chemistry of the earth. Part A-solid earth and geodesy, 25(1), 17-24. DOI: 10.1016/S1464-1895(00)00004-1

Andersen, O.B., Knudsen, P. and Trimmer, R. (2005). Improved high resolution altimetric gravity field mapping (KMS2002 global marine gravity field, Book Series: International Association of Geodesy Symposia, 128, 326-331. 
Andersen, O. B. and Cheng, Y. (2013). Long term changes of altimeter range and geophysical corrections at altimetry calibration sites. Advances in Space Research, 51(8), 1468-1477. DOI:10.1016/j. asr.2012.11.027

Andersen, O.B., Knudsen, P., Kenyon, S. and Holmes, S. (2014). Global and arctic marine gravity field from recent satellite altimetry (DTU13). 76th European Association of Geoscientists and Engineers Conference and Exhibition 2014: Experience the Energy - Incorporating SPE EUROPEC 2014, pp. 3049-3053. DOI: 10.3997/2214-4609.20140897

Bosch, W., Dettmering, D. and Schwatke, C. (2014). Multi-mission cross-calibration of satellite altimeters: constructinga long-term data record for global and regional sea level change studies. Remote Sensing, 6, 2255-2281. DOI: 10.3390/rs6032255

Cheng, Y., Andersen, O.B. (2012). A new global ocean tide model and its improvements in shallow water and the Polar Regions. Advances in Space Research, 50 (2012), 1099-1106. DOI: 10.1016/j. asr.2011.11.016

Deng, X., Andersen, O. B., Cheng, Y., Stewart, M. G. and Gharineiat, Z. (2012). Estimation of extreme sea levels from altimetry and tide gauges at the coast. 6th Coastal Altimetry Workshop, Riva Del Garda (Italy), 20-21 September 2012.

Garcia, E., Smith, W. H. F., Sandwell, D. T. (2014). Retracking CryoSat-2, Envisat, and Jason-1 Radar Altimetry Waveforms for Improved Gravity Field Recovery. Geophysical Journal International, 196 (3), 1402-1422. DOI: $10.1093 /$ gji/ggt469

Gharineiat, Z. and Deng, X. (2015). Application of the Multi Adaptive Regression Splines to integrate sea level data from altimetry and tide gauges for monitoring extreme sea level events. Marine Geodesy, 38(3), 261-276, DOI: 10.1080/01490419.2015.1036183

Hwang, C., Hsu, H.J., Chang, E.T.Y., Featherstone, W.E., Tenzer, R., Lien, T.Y., Hsiao YS, Shih HC and Jai P.H. (2014). New free-air and Bouguer gravity fields of Taiwan from multiple platforms and sensors. Tectonophysics, 61, 83-93. DOI: 10.1016/j.tecto.2013.11.027

Idris, N.H. and Deng, X. (2012). The retracking technique on multi-peak and quasi-specular waveforms for Jason-1 and Jason-2 mission near the cost. Marine Geodesy, 35(S1), 217-237. DOI: 10.1080/01490419.2012.718679

Knudsen, P, Bingham, R., Andersen, O. and Rio, M-H. (2011). A global mean dynamic topography and ocean circulation estimation using a preliminary GOCE gravity model. Journal of Geodesy, 85, 861-879. DOI: 10.1007/s00190-011-0485-8

Lee, H.K., Shum, C.K., Tseng, K.H., Huang, Z. and Sohn, H.G. (2013). Elevation changes of Bering Glacier System, Alaska, from 1992 to 2010, observed by satellite radar altimetry. Remote Sensing of Environment, 132: 40-48. DOI: 10.1016/j.rse.2013.01.007

Mayer-Gürr, T., Savcenko, R., Bosch, W., Daras, I., Flechtner, F. and Dahle Ch. (2012). Ocean tides from satellite altimetry and GRACE. J. Geodynamics, pp. 59-60. DOI: 10.1016/j.jog.2011.10.009

Richter, A., Mendoza, L., Perdomo, R., Hormaechea, J.L., Savcenko, R., Bosch, W. and Dietrich, R. (2012). Pressure tide gauge records from the Atlantic shelf off Tierra del Fuego, southernmost South America. Continental Shelf Res., 42, 20-29. DOI: 10.1016/j.csr.2012.03.016

Sandwell, D.T., Müller, R.D., Smith, W.H.F., Garcia, E. and Francis, R. (2014). New global marine gravity model from CryoSat-2 and Jason-1 reveals buried tectonic structure, Science, 346 (6205), 65-67. DOI: 10.1126/science.1258213

Savcenko, R. and Bosch, W. (2012). EOT11a - Empirical Ocean Tide Model From Multi-Mission Satellite Altimetry, DGFI Report No. 89.

Singh, A., Seitz, F. and Schwatke, C. (2012). Inter-annual water storage changes in the Aral Sea from multi-mission satellite altimetry, optical remote sensing, and GRACE satellite grawimetry. Remote Sensing of Environment, 123, 187-195. DOI: 10.1016/j.rse.2012.01.001

Stammer, D., Ray, R.D., Andersen, O.B., Arbic, B.K., Bosch, W., Carrère, L., Cheng, Y., Chinn, D.S., Dushaw, B.D., Egbert, G.D., Erofeeva, S.Y., Fok, H.S., Green, J.A.M., Griffiths, S., King, M.A., Lapin, V., Lemoine, F.G., Luthcke, S.B., Lyard F., Morison J., Müller M., Padman L., Richman J.G., 
Shriver J.F., Shum, C.K., Taguchi, E. and Yi, Y. (2014). Accuracy assessment of global barotropic ocean tide models, Reviews of Geophysics 52(3), 243-282. DOI: 10.1002/2014RG000450

Sulistioadi, Y., Tseng, K. Shum, C., Hidayat, H., Sumaryono, M., Suhardiman A. and Sunarso, S. (2015). Satellite radar altimetry for monitoring small rivers and lakes in Indonesia, Hydrology and. Earth System Sciences, 19(1), 341-359. DOI: 10.5194/hess-19-341-2015

Tseng, K.H., Shum, C., Yi, Y., Lee, H., Cheng, X. and Wang X. (2013). Envisat Altimetry Radar Waveform Retracking of Quasi-Specular Echoes Over Ice-Covered Qinghai Lake, Terrestrial Atmospheric and Oceanic Sciences (TAO), 24(4) Part I, pp. 615-627. DOI: 10.3319/TAO.2012.12.03.01(T1bXS)

Wang, X.W., Cheng, X., Gong, P., Shum, C., Holland, D.M. and Li, X.W. (2014). Freeboard and mass extraction of the disintegrated Mertz Ice Tongue with remote sensing and altimetry data. Remote Sensing of Environment, 144, 1-10, DOI: 10.1016/j.rse.2014.01.002

Yang, Y., Hwang, C., Hsu, H.J. and D E Wang, H. (2011). A sub-waveform threshold retracker for ERS-1 altimetry: a case study in the Antarctic Ocean. Computers \& Geosciences, 54(1), 113-118, DOI: $10.1016 /$ j.cageo.2011.08.017 